\title{
Tempo na ou da justiça criminal brasileira: uma discussão metodológica
}

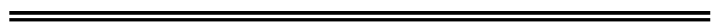 \\ Ludmila Ribeiro \\ Centro de Documentação e Pesquisa de História Contemporânea de Brasil (CPDOC) \\ Fundação Getúlio Vargas \\ Igor Machado \\ Doutorando em Sociologia pelo IESP/UERJ \\ Centro de Estudos de Direito e Sociedade (CEDES) \\ Klarissa Silva \\ Doutoranda em Sociologia pela UFRJ \\ Núcleo de Estudos da Cidadania, Conflito e Violência Urbana (NECVU)
}

\begin{abstract}
Resumo: A proposta deste artigo é discutir a relação entre tempo e direito a partir da problematização das metodologias empregadas no cálculo do tempo de processamento criminal. Essa discussão é importante porque, dependendo dos procedimentos empregados na construção e manuseio da base de dados (construída ou eleita para esse tipo de estudo), a medida final do tempo pode ser distinta e, por conseguinte, representar fenômenos diferenciados. Longe de evidenciar conclusões sobre qual a melhor forma de empreender esse tipo de análise ou de compreender o fenômeno do tempo da justiça, este artigo espera contribuir com o crescente interesse sobre o tema, apresentando questões e alternativas a todos aqueles que pretendem se dedicar à mensuração do processo de aplicação de normas no âmbito dos tribunais brasileiros.
\end{abstract}

Palavras-chave: metodologia; sociologia dos tribunais; tempo da justiça

Abstract: This article aims to discuss the relation between time and Law. It arises from problems in the methodologies usually applied to measure the length of criminal prosecution in Brazil and it is important because the findings of researches about that subject depend on the methodological procedures chosen for the data construction and handling, showing different results and different phenomena according to the methodologies applied. The article does not offer a final conclusion about what is the best way to analyze time in judicial cases, but aims to contribute with the growing interest in the subject of measurement of Law's time, highlighting questions and alternatives for those who must deal with the problem of measure time in prosecutions, especially in Brazilian courts.

Keywords: methodology; sociology of courts; time of justice

OPINIÃO PÚBLICA, Campinas, vol. 18, n², novembro, 2012, p. 355-382 
OPINIÃO PÚBLICA, Campinas, vol. 18, n², novembro, 2012, p. 355-382

Introdução ${ }^{1}$

Diariamente, são muitas as notícias que acionam no imaginário popular a ideia de que o sistema de justiça criminal brasileiro é moroso. Talvez, do ponto de vista simbólico, o exemplo mais evidente seja do jornalista Pimenta Neves que, em 20 de agosto de 2000, assassinou a sua namorada com dois tiros e, apesar de ter sido preso em flagrante e assim permanecido por sete meses, sua sentença condenatória final apenas foi decretada em 24 de maio de 2011, ou seja, quase dez anos após o crime. Do ponto de vista objetivo, a última mensuração do Índice de Confiança na Justiça (ICJ) da Fundação Getúlio Vargas (FGV) denotou que considerando a velocidade com que os casos são julgados, $53 \%$ dos brasileiros consideram o desempenho da justiça criminal regular, $22 \%$ avaliam como bom o seu desempenho, e os outros 25\% o consideram ruim (RELATÓRIO ICJ, BRASIL; $3^{\circ}$ trimestre de 2011).

No entanto, quais são os elementos que permitem dizer que a justiça criminal é morosa? Qual é a medida, do ponto de vista objetivo, que aciona imagens simbólicas relacionadas ao precário funcionamento do sistema de justiça criminal? Essas são questões que ainda permanecem sem uma resposta mais objetiva, do ponto de vista das balizas que devem ser consideradas para que essa problematização possa ser adequadamente administrada viabilizando, por conseguinte, a institucionalização de uma justiça rápida e percebida enquanto tal pela sociedade.

É importante salientar, contudo, que esses questionamentos não são novos. Desde os gregos, buscava-se um equilíbrio entre a temperança (que é a sabedoria do tempo) e a justiça (que é a sabedoria do direito). O grande problema teórico-metodológico de análises que pretendem abordar esse problema se refere ao fato de que o tempo é uma instituição social, em detrimento de ser um fenômeno objetivo ou uma experiência psíquica. Assim, independentemente de se analisado sobre a sua dimensão objetiva (número de dias transcorrido) ou sobre a sua dimensão subjetiva (sentimento relacionado ao número de dias transcorrido), o tempo do direito é uma construção social, já que ele não é algo exterior à matéria jurídica - como um simples conjunto de regras que prescreve a cronologia de uma série de ações. 0 tempo é, portanto, parte do próprio direito. Exatamente por isso, é preciso reificar a ideia de que não é possível dizer o direito senão dando o tempo, afinal, "o tempo é um dos maiores desafios da capacidade instituinte do direito" (OST, 2005, p. 14).

Nesse sentido, o tempo de processamento de um crime fornece uma boa aproximação daquilo que se denomina de tempo próprio mobilizado pela operação da norma jurídica, de tempo revelador do direito, de tempo que faz surgir, principalmente, a confiança (boa-fé, lealdade), na base de todos os comprometimentos jurídicos, do mesmo modo que a pertinência da concepção de "ajuste" contínuo, mais do que uma sucessão irregular de atos jurídicos instantâneos.

Assim, a primeira questão que se coloca seria, portanto, qual é a medida razoável do tempo de processamento de um crime? Essa pergunta é de suma importância para um sistema que segue a tradição jurídica da Civil $L a W^{2}$ porque, idealmente, nessa realidade, todos os tempos encontram-se

\footnotetext{
1 Uma primeira versão deste artigo foi apresentada no XV Congresso da Sociedade Brasileira de Sociologia. Uma versão ainda mais preliminar foi publicada no número 99 da Revista Jurídica da Presidência. Este artigo, contudo, é produto das diversas observações críticas recebidas por ocasião dessas duas publicações anteriores. Logo, agradecemos a todos aqueles que nos ajudaram com comentários diversos para que essa última versão pudesse ser produzida.

2 Para um detalhamento das características desse tipo de tradição jurídica, especialmente no Brasil, ver Kant de Lima (2008).
} 
RIBEIRO, L.; MACHADO, I.; SILVA, K. Tempo na ou da justiça criminal brasileira...

minimamente previstos em um diploma legal que, independente da situação ou do envolvido, deve ser aplicado da mesma forma, não sendo possível a sua negociação ou muito menos a sua transformação, já que:

\footnotetext{
"No âmbito do direito positivo, o tempo do processo judicial é o tempo diferido, encarado como sinônimo de segurança e concebido como uma relação de ordem e autoridade, representada pela possibilidade de esgotamento de todos os recursos e procedimentos numa ação judicial. Cada parte, intervindo no momento certo, pode apresentar seus argumentos e ter a garantia de ser ouvida na defesa de seus interesses. O tempo diferido é utilizado como instrumento de certeza, na medida em que impede a realização de julgamentos precipitados, sem o devido distanciamento com relação aos acontecimentos que deram margem à ação judicial" (FARIA, 2004, p. 04).
}

Contudo, o que se observa na realidade do funcionamento dos sistemas de justiça criminal é que nem sempre essa promessa, contida nos sistemas de justiça inspirados na tradição Civil Law, encontra respaldo na realidade cotidiana, sendo que os prazos efetivados pelas diversas organizações que compõem esse sistema estão longe de seguirem a previsibilidade almejada. Ou seja, nem sempre o tempo físico do código encontra correspondente no tempo físico do próprio tribunal e, quiçá, na ideia de tempo metafísico que norteia a própria noção de Justiça em uma dada sociedade.

A questão que se coloca não é, portanto, a ausência de conexão entre o tempo previsto no código e o efetivado na realidade cotidiana das organizações que compõem o sistema de justiça criminal e, ainda, as consequências dessa não aderência em termos do significado da "justiça" para os envolvidos. Isso porque o número de dias despendido desde o início até o fim do processamento não é apenas uma medida da eficiência dessas organizações, mas, sobretudo, uma medida da capacidade dessa sociedade em cumprir acordos, em manter a ordem, em efetivar os direitos da cidadania civil tal como inscritos no ideário republicano que é compartilhado não apenas em códigos jurídicos como em termos de valores que perpassam a consciência de todos os membros da sociedade. Nesse sentido, temse, inclusive, o referente mais citado nas pesquisas brasileiras sobre a construção social do tempo do sistema de justiça criminal:

\footnotetext{
"A dessincronia entre os tempos sociais em presença constitui-se por excesso ou por defeito num elemento sociologicamente relevante na reflexão sobre os conflitos e suas formas de resolução. Deste modo, podemos considerar que o tempo da justiça pode ser um tempo de cidadania socialmente útil quando compagina a resolução célere de um delito com a segurança jurídica das partes, mas também pode ser um tempo perverso quando constrange a procura de justiça, introduzindo desnecessariamente a morosidade na resolução de um litígio" (FERREIRA e PEDRoso, 1997, p. 04).
}

Logo, se o tempo do direito importa, os procedimentos empregados em sua mensuração são ainda mais importantes e, assim, ao invés de problematizar se o tempo despendido pelo sistema de 
OPINIÃO PÚBLICA, Campinas, vol. 18, n², novembro, 2012, p. 355-382

justiça criminal brasileiro no processamento de um delito o classifica em moroso ou não moroso, o objetivo deste artigo é discutir como essas estratégias de mensuração são construídas, questão essa que envolve distintos procedimentos desde a escolha do fenômeno criminal a ser estudado, perpassando pelo momento de processamento que se pretende analisar, seleção dos casos que serão analisados e, por fim, as técnicas empregadas em tal mensuração.

Nesse sentido, este artigo pretende problematizar a importância dos procedimentos metodológicos envolvidos no cálculo do tempo da justiça criminal, já que algumas análises realizadas nessa seara parecem ignorar que o resultado (em número de dias) é também produto de escolhas como: 1) que casos serão analisados e 2) qual será a técnica empregada para essa análise.

Para a realização dessa discussão, este artigo encontra-se dividido em três seções. A primeira apresenta o sistema de justiça criminal brasileiro e as pesquisas já realizadas nesse cenário que tiveram como objetivo mensurar o tempo do processamento de crimes como estupro e homicídio, com o propósito não apenas de demonstrar o crescente interesse pelo tema, como também, os processos metodológicos de construção da base de dados utilizada nas análises e das técnicas empregadas para mensuração do tempo.

Em seguida, as bases de dados referentes aos casos de homicídio doloso registrados entre os anos de 2000 e 2009 nos Tribunais de Justiça do Rio de Janeiro (TJRJ) e São Paulo (TJSP), acessadas a partir da pesquisa "Pensando o Direito: os novos procedimentos penais" ${ }^{3}$, são escrutinadas de diferentes formas. Com isso, pretende-se problematizar como o tempo do processo penal pode ser representado numericamente de maneira diferenciada dependendo da técnica utilizada. Em suma, se métodos diferentes levam a resultados distintos, o intento aqui é verificar quais são os pontos fortes e fracos de cada qual para eleger-se o que melhor se aplica ao problema em análise.

Por fim, são apresentadas algumas questões que merecem uma reflexão mais profunda, quando se problematiza a questão do tempo da, ou na, justiça, incluindo a necessidade de embate, dentro do direito, das noções de tempo cronológico e tempo adequado, traduzidas nas noções gregas de "Chronos" e "Kairós".

\section{Como o tempo do processamento penal tem sido mensurado no Brasil?}

Mensurar o tempo de processamento de um delito no Brasil não é tarefa fácil. O ponto principal de toda essa complicação é o fato de o sistema de justiça criminal ser caracterizado por um emaranhado de organizações articuladas na produção de um "mosaico de verdades" (KANT DE LIMA, 1989) e sem um sistema de estatística que viabilize tanto o monitoramento dos caminhos percorridos pelos papéis e pessoas, como ainda a mensuração das temporalidades envolvidas nessas atividades (VARGAS et al, 2010).

Nesses termos, o ponto de partida de qualquer análise dessa natureza é a apresentação dos caminhos que um delito pode percorrer desde o seu registro na polícia até o seu sentenciamento pelo

\footnotetext{
${ }^{3} 0$ relatório desta pesquisa é o volume $n^{\circ} .23$ da Coleção Pensando o Direito, produzida pela Secretaria de Assuntos Legislativos do Ministério da Justiça. Este material pode ser obtido a partir do link: <http://portal.mj.gov.br/main.asp?Team=\%7B7393FACA\%2DF9C1\%2D42B0\%2DBE43\%2D8F8756A587C8\%7D>. Os três autores deste artigo participaram efetivamente deste empreendimento.
} 
RIBEIRO, L.; MACHADO, I.; SILVA, K. Tempo na ou da justiça criminal brasileira...

Judiciário, sendo este tipo de estudo o que se convencionou denominar na literatura brasileira de fluxo do sistema de justiça criminal (VARGAS, 2004). Já essa expressão pode ser entendida como a conexão entre as polícias (Militar e Civil), o Ministério Público, a Defensoria Pública, o Judiciário e o Sistema Prisional, no intuito de processar as condutas capituladas como crime no Código Penal Brasileiro (CPB), de acordo com os procedimentos legais estabelecidos no Código de Processo Penal (CPP). Esse arranjo pode ser vislumbrado na Figura 1:

Figura 1

Sistemática de funcionamento da justiça criminal brasileira, apresentando o papel de cada instituição em uma organização linear no momento em que ela atua

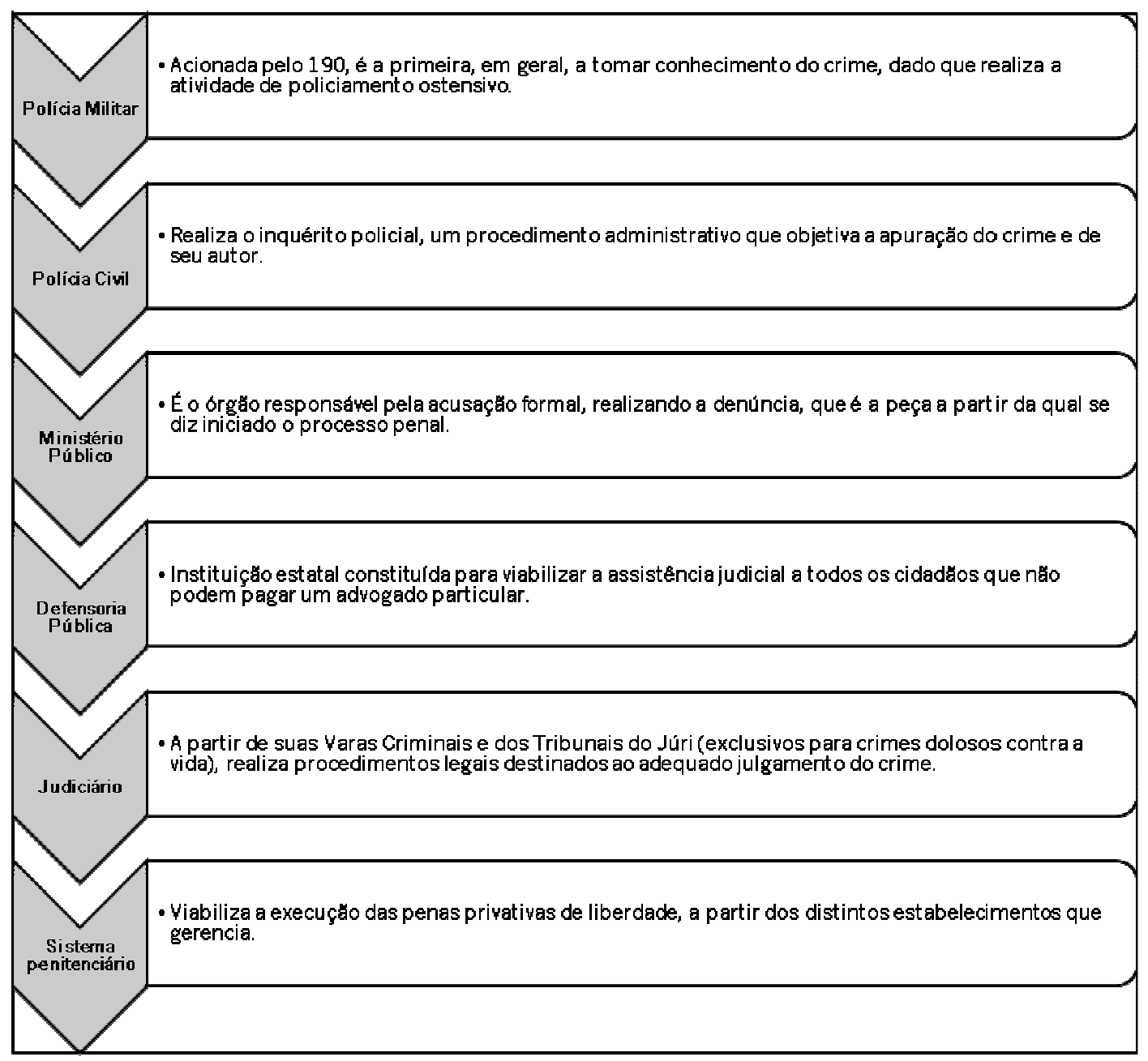

Fonte: Ribeiro (2010, p. 160). 
OPINIÃO PÚBLICA, Campinas, vol. 18, n², novembro, 2012, p. 355-382

A Figura 1 denota que a movimentação do sistema de justiça criminal brasileiro se inicia a partir da operação da organização encarregada de selecionar, no campo social, os acontecimentos cujas características permitem a sua categorização como um crime. Essa primeira organização é a Polícia Militar, que atende os chamados telefônicos da população "denunciando" a ocorrência de um crime e também realiza o patrulhamento ostensivo, momento em que se pode deparar com diversas atividades criminosas, registrando-as prontamente.

A Polícia Militar, que não tem atribuições investigativas, deve comunicar a ocorrência do suposto crime à Polícia Civil, a qual cabe verificar se a queixa tem fundamento e, nesse caso, buscar indícios e evidências da autoria e da materialidade do delito. À fase policial, de formulação do inquérito, segue a processual, que tem início com a denúncia formalizada pelo Ministério Público. A essa peça seguem-se o interrogatório do preso, a oitiva das testemunhas e a defesa prévia realizada pela Defensoria Pública ou por um advogado particular.

A fase judicial, por sua vez, culmina em uma sentença que absolve ou condena o réu de um determinado crime. Na hipótese de o desfecho do caso ser a condenação à pena privativa de liberdade, o caso é encaminhado para o sistema penitenciário, que administra uma série de estabelecimentos prisionais. Caso a pena seja restritiva de direitos, o indivíduo será encaminhado para uma central de penas e medidas alternativas à prisão4 .

Logo, idealmente, qualquer pesquisador que pretendesse analisar o tempo de processamento de um delito deveria ser capaz de reconstituir esse fluxo de processamento de papéis e pessoas (tal como descrito no Quadro 1), podendo temporalizar não apenas o número de dias envolvido em cada etapa, como ainda, os dias despendidos no intercâmbio de papéis entre as organizações. Nesse cenário hipotético, o cálculo do tempo de processamento seria possível dada a existência de um sistema que organizaria os dados quantitativos que o sistema produz no fluxo de decisões tomadas nas diferentes organizações de que este se compõe (FUNDAÇÃo JoÃo PINHEIRO, 1987 apud VARGAS, 2004).

\section{Quadro 1}

\section{Modelo de informações sobre fluxos e taxas de produção da Justiça Criminal}

\begin{tabular}{|l|l|l|}
\hline SEGMENTO ORGANIZACIONAL & PAPÉIS & PESSOAS \\
\hline Polícia Militar & Ocorrências & Prisões \\
Polícia Civil & Ocorrências / Inquéritos & Indiciados/Implicados \\
Disque-Denúncia & Denúncias & Denunciados/Acusados \\
Secretaria de Administração Prisional & Prontuários & \\
\hline
\end{tabular}

\footnotetext{
4 É importante destacar que até 1998, quando a parte relacionada à sistemática de penas do Código Penal Brasileiro (CPB) foi reformada, a pena privativa de liberdade era a principal modalidade de punição dos condenados pela prática de um crime. Contudo, desde então, têm crescido em todo país as Centrais de Acompanhamento das Penas e Medidas Alternativas (CEAPA), as quais têm como objetivo verificar a execução das penas restritivas de direitos e, dessa forma, impedir que as penas alternativas à prisão transformem-se em mecanismos de impunidade. Ocorre que, em distintos estados do país, a CEAPA ainda não se faz presente e, dessa forma, alguns juízes acabam preferindo sentenciar o indivíduo à privação de liberdade em detrimento à restrição de direitos, razão pela qual, nos desenhos mais tradicionais de representação do Sistema de Justiça Criminal brasileiro, a CEAPA ainda não é inserida.
} 
RIBEIRO, L.; MACHADO, I.; SILVA, K. Tempo na ou da justiça criminal brasileira...

Contudo, a principal dificuldade para a operacionalização de estudos sobre o sistema de justiça criminal no Brasil diz respeito à inexistência de um sistema oficial de estatística que congregue informações sobre todas as fases do fluxo, desde a policial até a do sistema prisional. 0 que existe são as bases de dados de cada organização, que são fragmentadas, produzidas de acordo com a lógica da agência em questão e segundo a natureza dos documentos que interessam em cada fase de processamento, sem a preocupação com o desdobramento desse dado nas fases posteriores.

Devido à inexistência de um código, uma variável-chave, que viabilize a conexão dessas diferentes bases de dados, torna-se inviável organizá-las em um fluxo semelhante ao descrito na Figura 1. Assim, quando essas são contrastadas com o objetivo de se produzir uma sequência concatenada de informações sobre o processamento do delito, desde a sua ocorrência até o seu sentenciamento, o resultado é um emaranhado de inconsistências, posto que os sistemas de dados computam fenômenos diferentes sob nomes semelhantes ou ainda fenômenos semelhantes sob nomes distintos (LIMA e SINHORETTO, 2010).

Exatamente por isso, poucas são as iniciativas existentes no sentido de integrar uma ou mais bases de dados oficiais com o objetivo de reconstruir o fluxo de papéis e pessoas referido por Vargas (2004). A única iniciativa existente no Brasil nesse sentido foi a empreendida pela Fundação SEADE, que concatenou os bancos de dados da Polícia Civil, do Judiciário e do Sistema Prisional para crimes ocorridos (independentemente do seu desfecho) entre os anos de 1991 e 1998. As análises produzidas a partir dessas bases de dados encontram-se retratadas em Lima e Sinhoretto (2010), Ribeiro (2010) e Vargas et al (2010).

Diante de tantos percalços nessa tarefa de articular sistemas de informações de organizações que são frouxamente articuladas de uma maneira funcional, pode-se dizer que os pesquisadores brasileiros têm se dividido em duas classes: uma que analisa apenas uma base de dados, localizando a contagem da movimentação de papéis e pessoas em apenas uma fase do fluxo e outra que procura construir a sua própria base de dados a partir da consulta aos distintos documentos produzidos pelo sistema de justiça criminal em cada fase para, com isso, reconstituir o fluxo.

É importante destacar que a opção de construir sua própria base de dados não significa que seja mais fácil obter e analisar as informações sobre fluxo de papéis e pessoas no sistema de justiça criminal. A primeira dificuldade encontrada está relacionada à própria autorização que o gerente do sistema (ou do arquivo no qual esses documentos jurídico-penais encontram-se armazenados) tem de conceder para que o pesquisador possa coletar os dados. Quando as barreiras superiores são vencidas, há inúmeras outras que necessitam ser enfrentadas, sendo um exemplo desse fenômeno a qualidade dos dados registrados nos documentos jurídico-penais. Em inúmeras situações, parece haver um esmero, até exagerado, no que concerne, por exemplo, às formalidades legais e administrativas. Tudo indica que, sobre elas, pesam os mais rigorosos controles. Em outras situações, porém, as informações são bastante precárias. Logo, é difícil decidir entre o que deve e o que não deve ser registrado. E, uma vez superados os obstáculos relacionados à coleta de informações, iniciam-se os problemas relacionados à interpretação do que esses dados querem dizer e das realidades que eles revelam. 
OPINIÃO PÚBLICA, Campinas, vol. 18, no 2, novembro, 2012, p. 355-382

Nesse sentido, quando o foco de análise passa a ser a temporalização do fluxo de papéis e pessoas no âmbito do sistema de justiça criminal, o que se percebe é que, nos últimos anos, um número crescente de autores tem se preocupado com essa temática. Para tanto, a maioria tem produzido bancos de dados com as informações necessárias para esse cálculo, os quais concentram-se no registro das movimentações relacionadas ao delito de homicídio doloso.

Nos estudos brasileiros, a escolha do crime é importante porque a legislação penal e processual penal dessa localidade estabelece ritos diferenciados, de acordo com a natureza do delito. Dentre os principais ritos existentes, cumpre destacar os seguintes: 1) os procedimentos processuais penais aplicáveis aos crimes punidos com reclusão; 2) os procedimentos processuais penais aplicáveis aos crimes punidos com detenção e prisão simples; e 3) os procedimentos aplicáveis aos crimes cuja pena máxima seja inferior a dois anos de prisão, os quais são processados de acordo com o previsto na lei 9.099/95, que regulamenta o funcionamento dos Juizados Especiais Criminais. A esses soma-se o procedimento aplicável aos crimes dolosos contra a vida, o qual é denominado rito do Tribunal do Júri.

A maior especificidade do rito do Tribunal do Júri está relacionada ao fato de que, nesse caso, na primeira fase do processamento, têm-se todos os atos processuais do rito ordinário, os quais são denominados de "sumário de culpa" e implicam não uma sentença de condenação ou de absolvição, mas uma decisão (pronúncia) que determina a realização do julgamento do réu pelo Tribunal do Júri. Como o crime de homicídio doloso é um dos poucos que se enquadra nessa categoria, a maioria dos pesquisadores opta por pesquisá-lo porque, nesse caso, eles serão capazes de compreender o que ocorre no fluxo mais longo de processamento.

Além disso, a maioria dos pesquisadores destaca que essa escolha deve-se ainda a maior confiabilidade que os dados desta natureza apresentam por se tratar de um dos crimes mais graves para a sociedade brasileira e que, por isso, tende a contar com um registro mais completo (em termos do seu andamento processual) em relação aos demais delitos (LIMA e SINHORETTO, 2010; VARGAS et al, 2010).

Uma vez escolhido o delito, a questão passa a ser onde coletar os documentos que sumarizam todas as fases do procedimento ora descrito. Percebe-se que, salvo raras exceções, a análise é de processos encerrados e arquivados em um dado período, já que esses casos não estão mais sujeitos à movimentação e ao acréscimo de novos "fatos" o que, por conseguinte, poderia implicar o aumento de um dado número de dias no tempo calculado. Com isso, torna-se possível mensurar o tempo do fluxo de processamento do homicídio doloso, desde o seu registro na polícia até a sua sentença no judiciário, com a atenção à possibilidade de se compreender os tempos de cada organização envolvida nessa atividade e, ainda, as idas e vindas entre estas.

De maneira geral, as pesquisas sobre esse tema, realizadas até o ano de 2010, encontram-se sumarizadas no Quadro 2, que apresenta também a delimitação da base de dados em termos de fonte, quantidade de casos analisados, medida de tempo encontrada e, ainda, técnica estatística empregada na contagem do tempo. 
RIBEIRO, L.; MACHADO, I.; SILVA, K. Tempo na ou da justiça criminal brasileira...

Quadro 2

Sumário das pesquisas empíricas sobre o tempo da justiça criminal. Brasil - 1999 a 2010

\begin{tabular}{|c|c|c|c|c|c|c|}
\hline $\begin{array}{l}\text { Referência } \\
\text { bibliográfica }\end{array}$ & $\begin{array}{l}\text { N. de } \\
\text { casos }\end{array}$ & Natureza dos casos analisados & $\begin{array}{l}\text { Recorte } \\
\text { temporal }\end{array}$ & $\begin{array}{c}\text { Base própria } \\
\text { ou dados } \\
\text { oficiais }\end{array}$ & $\begin{array}{c}\text { Tempo médio } \\
\text { de } \\
\text { processamento } \\
\text { (do fato à } \\
\text { sentença) } \\
\text { em dias }\end{array}$ & $\begin{array}{l}\text { Forma de } \\
\text { cálculo do } \\
\text { tempo }\end{array}$ \\
\hline $\begin{array}{l}\text { Pinheiro et al } \\
(1999)\end{array}$ & 28 & $\begin{array}{l}\text { Homicídios dolosos (linchamentos) ocorridos e } \\
\text { processados no estado de São Paulo }\end{array}$ & 1980-1989 & Base própria & 2230 & Média simples \\
\hline Vargas (2004) & 446 & \begin{tabular}{|l} 
Estupros registrados em delegacias \\
especializadas no atendimento à mulher em \\
Campinas em 1988 e acompanhados até 1999
\end{tabular} & 1988.1999 & Base própria & 1263 & $\begin{array}{c}\text { Análise de } \\
\text { sobrevivência }\end{array}$ \\
\hline $\begin{array}{l}\text { Vargas, } \\
\text { Blavatsky e } \\
\text { Ribeiro (2005) }\end{array}$ & 7226 & $\begin{array}{l}\text { Homicídios dolosos ocorridos e processados no } \\
\text { estado de São Paulo }\end{array}$ & $1991 \cdot 1998$ & Dados oficiais & 993 & Média simples \\
\hline $\begin{array}{l}\text { Vargas, } \\
\text { Blavatsky e } \\
\text { Ribeiro (2005) }\end{array}$ & 93 & $\begin{array}{l}\text { Homicídios dolosos cujo processo fora arquivado } \\
\text { em Campinas }\end{array}$ & 2003 & Base própria & 1648 & \\
\hline $\begin{array}{l}\text { Batitucci } \\
\text { et al(2006) }\end{array}$ & 90 & Homicídios dolosos arquivados em Minas Gerais & $1985 \cdot 2003$ & Base própria & 1611 & Média simples \\
\hline Ruschel (2006) & 17 & Homicídios dolosos julgados em Florianópolis & 2004 & Base própria & 784 & Média simples \\
\hline $\begin{array}{l}\text { Ribeiro e Duarte } \\
(2008)\end{array}$ & 624 & $\begin{array}{l}\text { Homicídios dolosos processados na cidade do } \\
\text { Rio de Janeiro }\end{array}$ & $2000 \cdot 2007$ & Dados oficiais & 707 & Média simples \\
\hline Ribeiro (2009) & 642 & \begin{tabular}{|l} 
Homicídios dolosos que receberam uma \\
condenação na cidade do Rio de Janeiro
\end{tabular} & $2002 \cdot 2004$ & Base própria & 1484 & Média simples \\
\hline Ribeiro (2009) & 131 & $\begin{array}{l}\text { Homicídios dolosos cujo processo foi arquivado } \\
\text { na cidade do Rio de Janeiro }\end{array}$ & 1996 & Base própria & 1915 & Média simples \\
\hline $\begin{array}{l}\text { Ribeiro, Cruz e } \\
\text { Batitucci (2009) }\end{array}$ & 51 & $\begin{array}{l}\text { Homicídios arquivados julgados na cidade de } \\
\text { Belo Horizonte }\end{array}$ & $1982 \cdot 2002$ & Base própria & 1580 & Média simples \\
\hline Silva $(2010)$ & 245 & $\begin{array}{l}\text { Homicídios denunciados no I e II Tribunal do Júri } \\
\text { de Belo Horizonte entre } 2003 \text { e } 2005\end{array}$ & $2003 \cdot 2009$ & Base própria & 1266 & Média simples \\
\hline
\end{tabular}

Fonte: elaboração dos autores.

Valendo-se da média de todos os casos registrados em tais sistemas, os pesquisadores têm constatado que a justiça brasileira pode ser caracterizada como morosa em tal atividade, posto que despende, para a realização dessa atividade, um número de dias muito superior ao previsto no Código de Processo Penal - que, para o caso do homicídio doloso, era de 310 dias até o ano de 2008 e após a lei 11.689/08 passou a ser de 315 dias $^{5}$ : 30 dias para o inquérito policial, 15 dias para o oferecimento da denúncia, 90 dias para encerramento da primeira fase de instrução e 6 meses para encerramento da fase do júri propriamente dita.

Em que pese a contribuição desse resultado, bem como do melhor entendimento dos determinantes do tempo de processamento desse crime (algo que todos os estudos supracitados realiza), o que poucos têm problematizado são os procedimentos metodológicos envolvidos tanto no processo de constituição das bases de dados, como na mensuração do tempo.

Em diversos casos, a amostra, além de pequena considerando todo o universo de processos existentes em um dado tribunal, não é construída de maneira adequada: ou seja, os casos não são selecionados a partir de múltiplos filtros (por exemplo, delegacia de origem, vara responsável pelo caso,

${ }^{5}$ Em 09/06/08, o presidente Lula sancionou o conjunto de proposições da mini-reforma do Código de Processo Penal. O também chamado "Pacote da Segurança" é composto por três projetos de lei (PLs): o 4203/01; o 4205/01; e o 4207/01. O PL 4203/01 transformou-se na lei 11.689/08 e alterou o funcionamento do Tribunal do Júri demarcando prazos mais precisos para cada ato da fase judicial. Já o PL 4205/01 transformou-se na lei 11.690/08, definindo e proibindo a produção de provas por meios ilícitos, incluindo a prova ilícita por derivação e esclarecendo sobre as provas antecipadas, pericial e testemunhal. Por sua vez, o PL 4207/01 transformou-se na lei 11.719/08 e definiu, entre outros pontos, prazos mais precisos para o processamento ordinário, ao que se sujeita a grande maioria dos crimes "comuns". 
OPINIÃO PÚBLICA, Campinas, vol. 18, no 2, novembro, 2012, p. 355-382

promotor sorteado para acompanhá-lo, dentre outros). Dessa forma, os elementos que podem interferir ou determinar o resultado "tempo" não são, necessariamente, levados todos em consideração, o que, por sua vez, pode enviesar o resultado (no caso, o número de dias da fase).

Se essa estratificação progressiva de que fala Becker (2007) ao problematizar os requisitos da amostragem não é levada em consideração, a forma de sorteio dos casos também não é explicitada, o que também pode levar a vieses nos resultados. Em diversas situações, os pesquisadores terminam registrando os processos que os funcionários do arquivo ou do cartório disponibilizam a eles, pois é tão difícil chegar até esse ponto que é melhor aceitar essa limitação a não ter como concluir a pesquisa. Não raro as bases de dados referenciadas no Quadro 2 são produtos dos "50 primeiros casos" que chegaram ao conhecimento do cartório ${ }^{6}$, sem atentar que, em razão de programas como o Meta $2^{7}$ do Conselho Nacional de Justiça (CNJ), estes podem ser exatamente os casos que estavam no cartório há, pelo menos, cinco anos. Esse fenômeno, por si só, é um exemplo de como os tempos do processo penal podem ser "inflacionados" em razão da forma como a base de dados é construída.

Claro que esses problemas podem ser evitados quando se trabalha com os registros oficiais cedidos pelos tribunais. Mas, mesmo nesses casos, existem questões que podem enviesar a análise, dada a existência de métodos muito peculiares de inserção da informação nos sistemas oficiais. Por exemplo: a unidade de análise de alguns tribunais é o indivíduo que está sendo processado e não o caso (ou o processo), tal como ocorre em outros. Assim, como um mesmo processo pode ter dois réus, que foram denunciados e sentenciados no mesmo momento, a dupla contagem de um mesmo caso pode contribuir para a extensão do tempo médio (se forem dois casos excessivamente longos) ou para a sua redução (se forem dois casos excessivamente rápidos). Então, se o pesquisador que trabalhou com essa base de dados não descreve, por exemplo, que desconsiderou um dos réus para a análise do tempo do processo, a replicação do mesmo estudo por outros interessados nesse tema pode estar comprometida, já que esses podem terminar contando um mesmo caso duas vezes e, por conseguinte, distorcendo a média de tempo, dentre outras estatísticas relevantes.

Contudo, se os problemas relacionados ao processo de construção da base de dados parecem complexos demais para serem transpostos, as técnicas de análise de dados empregadas podem ser mais bem potencializadas se as possíveis distorções forem anteriormente problematizadas. Com esse objetivo, a próxima seção apresenta os procedimentos empregados para a análise do tempo de processamento dos casos de homicídio doloso iniciados nos tribunais de São Paulo e Rio de Janeiro entre os anos de 2000 e 2009, procurando demonstrar as potencialidades e limites de cada técnica.

\footnotetext{
6 Nesse sentido, é importante destacar que cada pesquisador deve eleger um critério para inserção dos casos em sua base de dados. Alguns criam uma planilha com os números de todos os processos arquivados naquele ano e, na coluna ao lado, colocam números aleatórios, o que os permite sortear, por exemplo, apenas aqueles casos identificados com números pares. Outros utilizam essa mesma organização dos números dos processos e elegem como critério a seleção dos 50 primeiros casos. Esses são alguns dos mecanismos encontrados para identificação dos casos com os quais se pretende trabalhar.

${ }^{7}$ Meta 2: "Identificar os processos judiciais mais antigos e adotar medidas concretas para o julgamento de todos os distribuídos até 31.12.2005 (em $1^{\circ}, 2^{\circ}$ grau ou tribunais superiores)". In: <www.cnj.jus.br>. Acesso em: 23 mar. 2009. pesquisador analisa apenas os 50 primeiros casos julgados a partir de 23 de março de 2009, quando essa resolução foi publicada, ele estará trabalhando apenas com os processos mais longos, que foram inseridos na pauta de julgamento com o objetivo de se responder às demandas do CNJ. Contudo, essa não é a realidade do tribunal, já que esse inclui tanto casos que ocorreram há poucos dias, como esses "em atraso", que se tornaram prioridade.
} 
RIBEIRO, L.; MACHADO, I.; SILVA, K. Tempo na ou da justiça criminal brasileira...

Afinal, como mensurar o tempo de processamento? 0 caso dos homicídios dolosos processados pelo TJRJ e TJSP

Os dados analisados nesta seção foram acessados no âmbito da Pesquisa "Pensando o Direito", executada ao longo dos anos de 2009 e 2010 pelo Centro de Estudos de Segurança e Cidadania (CESeC), da Universidade Candido Mendes (UCAM), a partir do financiamento da Secretaria de Assuntos Legislativos (SAL) do Ministério da Justiça (MJ). Esse estudo avaliou os efeitos da reforma do Código de Processo Penal brasileiro, realizada no ano de 2008, sobre o tempo do processo penal.

Logo, nesta seção, será analisado o sistema de informações oficial de apenas uma das organizações que compõem o sistema de justiça criminal e, por isso, a reconstituição de fluxo de papéis e pessoas dessa agência com as demais será feita apenas indiretamente, a partir dos registros que se encontram disponíveis no banco de dados cedido.

Outra ressalva importante, diz respeito à forma de construção da base, isto é, critérios de seleção dos casos que foram repassados, já que alguns vieses não puderam ser evitados. Nesse sentido, cumpre destacar que apesar de o pedido encaminhado ao TJSP e TJRJ explicitar que fossem repassadas as informações referentes a todos os casos de roubo e homicídio doloso iniciados entre 2000 e 2009, independente do seu desfecho, no caso do Rio de Janeiro, as informações encaminhadas correspondiam, majoritariamente, aos processos de roubo e homicídio doloso distribuídos e encerrados em primeira instância entre 01/01/2000 e 30/09/2009. Ou seja, foram repassados, em sua maioria, os dados referentes aos casos que alcançaram pelo menos alguma decisão. Já o banco de dados do TJSP compreendia, majoritariamente, os casos distribuídos entre janeiro de 2000 e dezembro de 2009, independente do seu desfecho, conforme solicitado.

Uma vez recebidos os bancos de dados, as tarefas seguintes foram: 1) calcular os tempos de cada uma das fases do processo penal, ou seja, o tempo do caso em cada uma das agências que compõem o sistema e entre elas e 2) contrastar esses tempos com o previsto pelo Código de Processo Penal.

Para cálculo dos tempos, foi necessário organizar o sistema de maneira que cada caso correspondesse a um registro. Como a proposta era enfatizar o fluxo de papéis no âmbito do judiciário, a unidade de análise foi o processo, o que implica dizer que os diversos casos que contavam com mais de um réu foram condensados em apenas um ${ }^{8}$. No caso de São Paulo, essa razão era de 1 processo para cada 1,14 réus e, no Rio de Janeiro, essa razão era de 1 processo para cada 1,5 réus de homicídios dolosos. Logo, nessa primeira etapa, as "perdas" foram as seguintes (Tabela 1):

\footnotetext{
${ }^{8}$ Dessa forma, o caso que permaneceu na base de dados foi aquele que possuía maior número de informações, ou seja, que apresentasse todas as datas necessárias para cálculo do tempo global e do tempo de cada fase de processamento.
}

365 
OPINIÃO PÚBLICA, Campinas, vol. 18, n², novembro, 2012, p. 355-382

Tabela 1

Distribuição dos números absolutos de processos e de indivíduos processados por homicídio doloso

Rio de Janeiro e São Paulo, Estado (2000 - 2009)

\begin{tabular}{|l|c|c|}
\hline Unidade & TJSP & TJRJ \\
\hline Indivíduos & 142.506 & 8.499 \\
\hline Processos & 124.835 & 5.671 \\
\hline Razão (indivíduo/processo) & 1,14 & 1,5 \\
\hline
\end{tabular}

O segundo procedimento foi verificar, da quantidade total enviada, quantos casos alcançaram a fase final de processamento, isto é, sentença absolutória ou condenatória, já que estes eram os casos com informações completas. Esse dado é importante porque a maioria das técnicas estatísticas existentes computa apenas esse tipo de caso para cálculo do tempo global de processamento. Contudo, antes de apresentar a discussão sobre as questões metodológicas envolvidas no cálculo do tempo propriamente dito, cumpre destacar quais são as principais fases de processamento, as quais serão utilizadas como balizas para a discussão da temporalidade dos atos processuais. Para tanto, tem-se a Figura 2: 
RIBEIRO, L.; MACHADO, I.; SILVA, K. Tempo na ou da justiça criminal brasileira...

Figura 2

Fases de um processo penal, para crimes de homicídio doloso, de acodo com o Código de Processo

Penal vigente (após a reforma de 2008) e sem considerar os recursos aplicáveis após a prática de cada ato

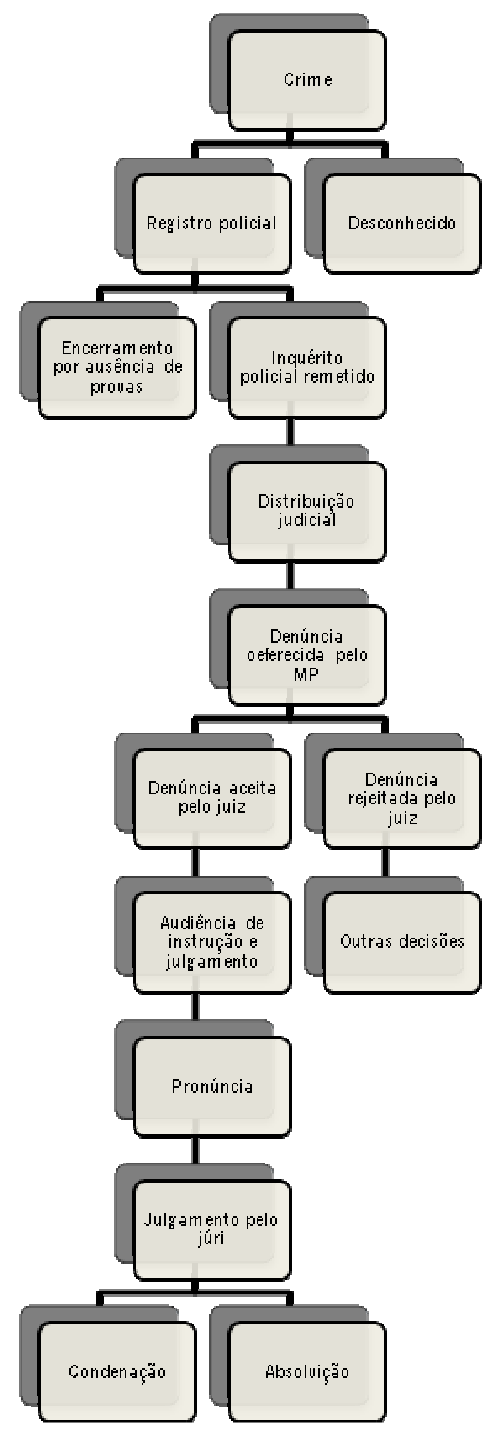

De acordo com Cano e Duarte (2010), quando se trabalha com dados oficiais, a tendência é possuir um grande número de casos iniciados (com o registro policial) e poucos casos encerrados (com o julgamento pelo júri) em cada ano. Vários são os fatores apontados para essas perdas. Os casos podem não possuir informações técnicas suficientes para seguirem no fluxo e, por isso, são arquivados 
OPINIÃO PÚBLICA, Campinas, vol. 18, nº 2, novembro, 2012, p. 355-382

em determinadas fases (isto é o que ocorre, por exemplo, quando há a rejeição da denúncia ${ }^{9}$ ). Pode ocorrer ainda de o réu morrer, motivo que leva ao encerramento do caso em uma dada fase sem prosseguimento à subsequente. E, por fim e mais problemático, pode ocorrer de o caso restar esquecido em uma das mesas ou cartórios judiciais, fazendo com que este não seja processado adequadamente pelo Tribunal de Justiça.

Logo, quando se pretende analisar o tempo de processamento a partir de uma base de dados oficial, o comum é ter duas curvas paralelas: uma mais elevada, com todos os casos distribuídos (isto é, inseridos no sistema do tribunal) e uma mais baixa, com os casos encerrados (isto é, sentenciados e, posteriormente, arquivados ou baixados). Contudo, se essa é a regra para a maioria dos bancos de dados cedidos por organizações judiciais, no caso desse estudo, essa regra foi adimplida apenas por São Paulo (Gráfico 1), já que, no caso do Rio de Janeiro (Gráfico 2), a curva de casos sentenciados se sobrepõe à curva de casos distribuídos, indicando que, ou o tribunal possui um padrão "muito acima da média" em termos de produção (posto que sentencia mais casos do que recebe nos últimos anos da série), ou o banco de dados foi gerado a partir de filtros sucessivos, que contemplavam não os casos iniciados no período, mas os iniciados e encerrados, o que dificulta o emprego de técnicas como a análise de sobrevivência (explicada adiante) no cálculo do tempo do processo.

\section{Gráfico 1}

Variação anual do número de processos de homicídios dolosos distribuídos e encerrados no período (independente de serem os mesmos) - Estado de São Paulo, jan/2000 a dez/2009

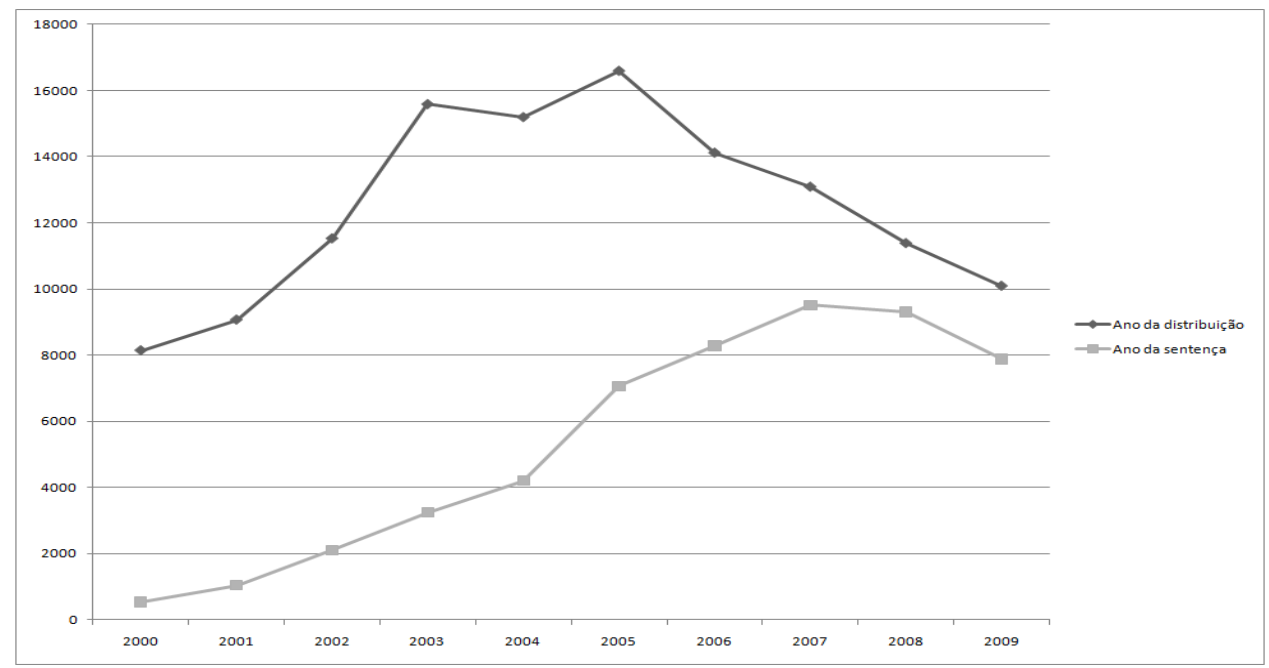

Fonte: Tribunal de Justiça do Estado de São Paulo.

\footnotetext{
${ }^{9} \mathrm{O}$ juiz pode não aceitar a denúncia oferecida pelo Ministério Público, de acordo com o art. 43 do CPP, que estabelece que "Art. 43. A denúncia ou queixa será rejeitada quando: I - o fato narrado evidentemente não constituir crime; II - já estiver extinta a punibilidade, pela prescrição ou outra causa; III - for manifesta a ilegitimidade da parte ou faltar condição exigida pela lei para o exercício da ação penal. Parágrafo único. Nos casos do no III, a rejeição da denúncia ou queixa não obstará ao exercício da ação penal, desde que promovida por parte legítima ou satisfeita a condição".
} 
RIBEIRO, L.; MACHADO, I.; SILVA, K. Tempo na ou da justiça criminal brasileira...

Gráfico 2

Variação anual do número de processos de homicídios dolosos distribuídos e encerrados no período (independente de serem os mesmos) · Estado do Rio de Janeiro, jan/2000 a set/2009

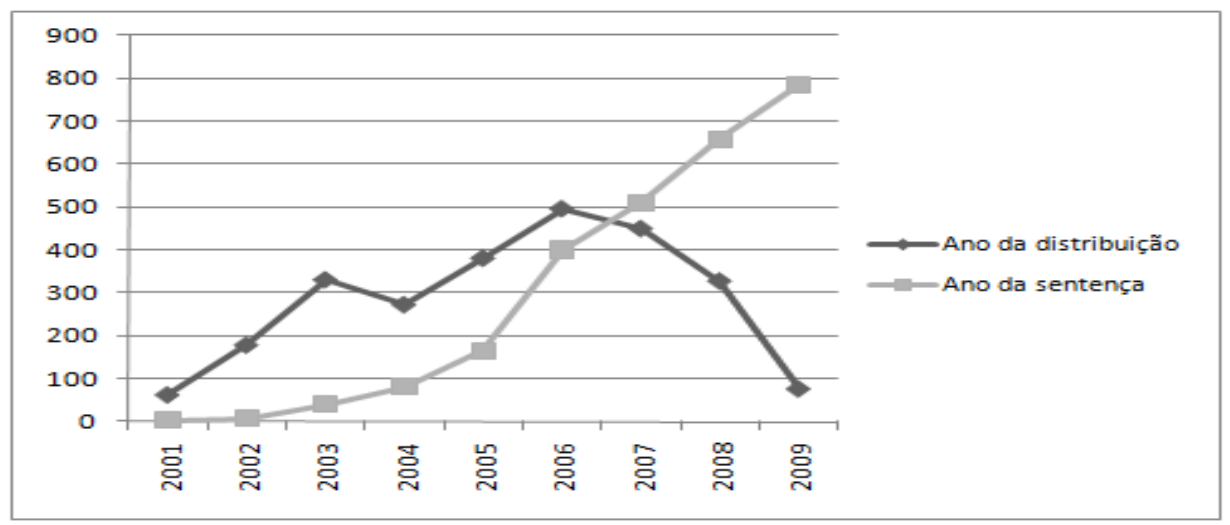

Fonte: Tribunal de Justiça do Estado do Rio de Janeiro.

Logo, enquanto no caso dos dados repassados pelo TJSP era adequado pressupor que se tratava de uma cópia fiel do sistema de informações, no caso do TJRJ, a hipótese era de que apenas os casos iniciados, mas que tivessem alcançado pelo menos uma decisão (ainda que fosse remetendo à segunda fase do processamento pelo júri) estavam contemplados no sistema. Assim, provavelmente, todos os casos iniciados em 2000 estavam sentenciados em 2009 e, por isso, contemplados no sistema. Mas os casos iniciados em 2009 que, em razão do pequeno lapso de tempo, não puderam ser sentenciados até a cessão do banco, não foram contemplados. Como depois de um tempo é normal que as sentenças aumentem, já que os casos vão esgotando todas as fases a serem percorridas, a explosão do ponto final dessa curva deve-se ao fato de que há mais sentenças referentes aos anos anteriores do que ao ano em questão.

Feitas essas ressalvas, cumpre destacar ainda que, para as análises seguintes, esta seção divide-se em dois momentos: o primeiro analisa apenas os casos com informações completas (isto é, data da distribuição e data da sentença) e os casos que possuem informações "censuradas" ou incompletas (posto que possuem a data da distribuição, mas não possuem a data da sentença, uma vez que não tinham alcançado essa fase quando da cessão da base), como indica a Tabela 2: 
OPINIÃO PÚBLICA, Campinas, vol. 18, n², novembro, 2012, p. 355-382

Tabela 2

Descrição do total de casos existente e total de casos com sentença terminativa (absolvição / condenação). Rio de Janeiro e São Paulo (2000 - 2009)

\begin{tabular}{|l|r|r|}
\hline Unidade & \multicolumn{1}{r|}{ TJSP } & \multicolumn{1}{l|}{ TJRJ } \\
\hline Processos iniciados & 124.835 & 5.671 \\
\hline Processos concluídos & 27.569 & 3.642 \\
\hline Razão (iniciados por concluído) & 5 & 2 \\
\hline
\end{tabular}

No segundo momento, considerando apenas os casos com informações completas, foram calculadas as estatísticas descritivas relacionadas ao tempo de cada fase do procedimento penal (Tabela 3):

\section{Tabela 3}

Estatísticas descritivas de tempo, de acordo com a fase do processamento em questão Rio de Janeiro e São Paulo (2000 - 2009)

\begin{tabular}{|c|c|c|c|c|c|c|}
\hline Intervalos de tempo & $\begin{array}{l}\mathrm{N} \\
(1)\end{array}$ & $\begin{array}{l}\text { Valor } \\
\text { Mínimo } \\
\text { (2) }\end{array}$ & $\begin{array}{l}\text { Valor } \\
\text { Máximo } \\
\text { (3) }\end{array}$ & $\begin{array}{l}\text { Média } \\
\text { (4) }\end{array}$ & $\begin{array}{c}\text { Desvio } \\
\text { Padrão } \\
\text { (5) }\end{array}$ & $\begin{array}{c}\text { Coeficiente } \\
\text { de } \\
\text { variação } \\
\text { (6) }\end{array}$ \\
\hline \multirow{4}{*}{$\begin{array}{l}\text { São Paulo } \\
\text { Tempo entre a data do crime e a data da distribuição } \\
\text { Tempo entre a data da distribuição e o recebimento } \\
\text { da denúncia } \\
\text { Tempo entre o recebimento da denúncia e a sentença } \\
\text { Tempo entre a distribuição e a sentença } \\
\text { Tempo entre a data do crime e a data da última } \\
\text { sentença }\end{array}$} & 23106 & 1 & 38515 & 609 & 1178 & 1,93 \\
\hline & 13635 & 1 & 2951 & 239 & 369 & 1,54 \\
\hline & 21709 & 1 & 39916 & 1314 & 1256 & 0,96 \\
\hline & & $\begin{array}{l}1 \\
6\end{array}$ & 39495 & 1530 & 1250 & 0,82 \\
\hline \multicolumn{7}{|l|}{ Rio de Janeiro } \\
\hline $\begin{array}{l}\text { Tempo entre a data do crime e a data da distribuição } \\
\text { do processo }\end{array}$ & 1427 & 1 & 18938 & 560 & 1158 & 2,07 \\
\hline $\begin{array}{l}\text { Tempo entre a data da distribuição do processo e a } \\
\text { data do recebimento da denúncia }\end{array}$ & 1474 & 1 & 3197 & 217 & 485 & 2,24 \\
\hline $\begin{array}{l}\text { Tempo entre a data do recebimento da denúncia e a } \\
\text { sentença }\end{array}$ & 1485 & 1 & 5173 & 413 & 453 & 1,10 \\
\hline $\begin{array}{l}\text { Tempo entre a data da distribuição e a data da } \\
\text { sentença }\end{array}$ & 3642 & 1 & 3518 & 950 & 701 & 0,74 \\
\hline $\begin{array}{l}\text { Tempo entre a data do crime e a data da última } \\
\text { sentença }\end{array}$ & 1457 & 36 & 19490 & 1503 & 1308 & 0,87 \\
\hline
\end{tabular}

A Tabela 3 apresenta na coluna (1) o valor de (N), que corresponde ao total de casos considerado para cálculo do tempo de cada uma das fases de processamento, no âmbito das duas bases de dados. Como se percebe, os números são diferentes em cada localidade (São Paulo e Rio de Janeiro) e ainda em cada fase, posto que um caso pode ter informações válidas para alguns pontos cruciais (por exemplo, data da distribuição e da sentença) e não para todas (pode faltar, por exemplo, a data do recebimento da denúncia).

Em seguida, na coluna (2), é apresentado o valor mínimo, que é o menor valor encontrado pela subtração da maior data pela menor data, considerando-se apenas os casos que possuíam informações 
RIBEIRO, L.; MACHADO, I.; SILVA, K. Tempo na ou da justiça criminal brasileira...

válidas para as duas datas. Logo, se a data que deveria ser maior era, na realidade, menor, indicando um problema de consistência no preenchimento do campo, o caso foi automaticamente excluído. Cumpre destacar que a maioria dos valores encontrados nessa coluna é 1 , indicando que os dois momentos processuais analisados como marco de início e de encerramento de cada fase ocorreram no mesmo dia.

A coluna (3) apresenta o valor máximo, que é o maior valor encontrado pela subtração da maior data pela menor data, considerando-se apenas os casos que possuíam informações válidas para as duas datas. Cumpre destacar que a maioria dos valores encontrados nessa coluna é superior a 3650, indicando que, em algumas situações, o trâmite dos processos de homicídio doloso nas duas localidades tem demorado mais de 10 anos.

A coluna (4) apresenta o valor médio, calculado somando-se todos os tempos (desde o valor mínimo até o valor máximo) e dividindo o resultado dessa soma pelo número de casos (N) existente. Logo, a média mostra-se problemática quando alguns casos possuem valores muito pequenos e outros extremamente elevados, pois o valor por ela apresentado será "distorcido" por suas extremidades. Assim, os dados apresentados na Tabela 3 são interessantes porque indicam que, apesar de o número de casos cedido para a análise de cada tribunal ser distinto, o padrão de processamento global parece não ser, já que o número médio de dias transcorrido entre a data do crime e a data da sentença em São Paulo foi de 1530 dias e no Rio de Janeiro, de 1503 dias. Já o tempo médio entre a data de distribuição e a data da sentença, que considera as informações "mais bem" preenchidas em termos de datas ${ }^{10}$, foi de 942 dias em São Paulo e 950 dias no Rio de Janeiro.

A coluna (5) apresenta o valor do Desvio Padrão, dado pela raiz quadrada da variância que, por sua vez, é a distância entre cada um dos valores de tempo e a média gerada. Se todos os casos analisados em cada uma das fases tivessem valores de tempo semelhantes ao tempo médio, a variância e, por conseguinte, o desvio padrão seriam iguais a zero. Logo, o desvio padrão é uma medida da capacidade da média em representar o fenômeno que se estuda. Uma forma de tornar essa análise mais palatável é utilizar os valores de média e desvio padrão para se calcular o coeficiente de variação.

Assim, na coluna (6) foi apresentado o coeficiente de variação, que constitui uma maneira de expressar a variabilidade dos dados tirando a influência da ordem de grandeza da variável. Seu cálculo é feito pela razão entre o desvio padrão e a média. Logo, essa medida indica qual é a distância média dos casos em relação à própria média e, assim, quanto mais próximo do valor 0 (zero), menor a variação dos casos em torno da média. Quanto maior do que 0 (zero), maior a variabilidade dos casos e menor a capacidade da média em ser uma boa medida do fenômeno.

Ao analisar os coeficientes de variação do tempo entre a data do crime e a data da sentença, percebe-se que a média não parece consubstanciar-se em uma boa medida do tempo despendido pelo sistema de justiça criminal para processamento do caso, posto que o coeficiente de variação para esses

\footnotetext{
10 A data de distribuição é a data de início do processo no judiciário. Usualmente, marca o dia em que o inquérito policial chegou ao judiciário e foi distribuído a um promotor para que esse pudesse oferecer a denúncia e essa, depois de aceita, pudesse iniciar o processo penal. Conquanto essas idas e vindas reflitam a dificuldade em se precisar a data de início desse processo penal, dado que a data da denúncia ou a data de recebimento da denúncia não é tão bem preenchida como a data da distribuição, para fins dessa análise, essa será utilizada como marco inicial do tempo do processo, dado que esse é o primeiro registro no judiciário.
} 
OPINIÃO PÚBLICA, Campinas, vol. 18, no 2, novembro, 2012, p. 355-382

casos alcançou valor de 0,82 em São Paulo e 0,85 no Rio de Janeiro. Cenário semelhante apresenta-se quando o tempo entre a data da distribuição e a sentença é levado em consideração, já que o coeficiente de variação apresentou valor de 0,80 e 0,70 para São Paulo e Rio de Janeiro, respectivamente.

$\mathrm{Na}$ tentativa de encontrar uma medida capaz de representar de maneira mais adequada o tempo que o sistema de justiça criminal despende no processamento de um delito, foram calculados os tempos médios e medianos transcorridos entre a data da distribuição e a data da sentença, em São Paulo e no Rio de Janeiro. Assim, além de problematizar uma medida válida do ponto de vista de todo o período analisado, procurou-se encontrar medidas acuradas para cada um dos anos em questão. 0 resultado segue na Tabela 4:

Tabela 4

Tempo médio de duração processos de homicídio doloso, segundo ano da distribuição Estados do Rio de Janeiro e de São Paulo - 2000 a 2009

\begin{tabular}{|c|c|c|c|c|c|c|c|}
\hline $\begin{array}{c}\text { Ano da distribuição } \\
\text { do processo }\end{array}$ & $\begin{array}{l}\mathbf{N} \\
(1)\end{array}$ & $\begin{array}{l}\text { Valor } \\
\text { Mínimo } \\
\text { (2) }\end{array}$ & $\begin{array}{l}\text { Valor } \\
\text { Máximo } \\
\text { (3) }\end{array}$ & $\begin{array}{c}\text { Mediana } \\
\text { (4) }\end{array}$ & $\begin{array}{l}\text { Média } \\
\text { (5) }\end{array}$ & $\begin{array}{l}\text { Desvio } \\
\text { Padrão } \\
\text { (6) }\end{array}$ & $\begin{array}{c}\text { Coeficiente de } \\
\text { variação } \\
(7)\end{array}$ \\
\hline São Paulo & & & & & & & \\
\hline 2000 & 2301 & 16 & 8111 & 1851 & 1764 & 1034 & 0,59 \\
\hline 2001 & 2650 & 17 & 3263 & 1543 & 1554 & 864 & 0,56 \\
\hline 2002 & 3356 & 3 & 2880 & 1242 & 1269 & 748 & 0,59 \\
\hline 2003 & 3660 & 15 & 2513 & 1036 & 1093 & 651 & 0,60 \\
\hline 2004 & 3629 & 3 & 2162 & 759 & 864 & 546 & 0,63 \\
\hline 2005 & 4143 & 2 & 1801 & 584 & 685 & 449 & 0,65 \\
\hline 2006 & 3351 & 1 & 1422 & 512 & 574 & 347 & 0,60 \\
\hline 2007 & 2686 & 2 & 1026 & 398 & 430 & 249 & 0,58 \\
\hline 2008 & 1403 & 4 & 706 & 283 & 299 & 160 & 0,53 \\
\hline 2009 & 390 & 2 & 318 & 129 & 136 & 76 & 0,56 \\
\hline Total geral & 27569 & 1 & 8111 & 726 & 942 & 754 & 0,80 \\
\hline Rio de Janeiro & & & & & & & \\
\hline 2000 & 363 & 58 & 3518 & 1480 & 1666 & 954 & 0,57 \\
\hline 2001 & 359 & 64 & 3127 & 1215 & 1348 & 797 & 0,59 \\
\hline 2002 & 685 & 23 & 2865 & 846 & 1014 & 686 & 0,68 \\
\hline 2003 & 608 & 2 & 2394 & 902 & 972 & 577 & 0,59 \\
\hline 2004 & 364 & 3 & 2041 & 841 & 914 & 549 & 0,60 \\
\hline 2005 & 439 & 5 & 1707 & 684 & 734 & 458 & 0,62 \\
\hline 2006 & 379 & 1 & 1385 & 654 & 655 & 363 & 0,55 \\
\hline 2007 & 272 & 2 & 918 & 532 & 503 & 223 & 0,44 \\
\hline 2008 & 134 & 2 & 622 & 309 & 307 & 163 & 0,53 \\
\hline 2009 & 39 & 2 & 251 & 89 & 85 & 75 & 0,89 \\
\hline Total geral & 3642 & 1 & 3518 & 776 & 950 & 701 & 0,74 \\
\hline
\end{tabular}

Várias são as questões interessantes que a Tabela 4 apresenta. Primeiro, cumpre destacar a nova medida estatística apresentada na coluna (4), qual seja, a mediana. Esta é o valor do caso intermediário na distribuição quando todos os casos são organizados em uma ordem crescente (do menor para o maior). O caso intermediário é aquele que divide a distribuição (ou todos os tempos mensurados naquela fase) pela metade, com número igual de casos com valor acima e abaixo do mesmo. Logo, essa é uma medida que não é "distorcida" pela existência de valores elevados ou muito baixos, pois o que está sendo considerado é a quantidade de casos $(\mathrm{N})$, sendo que a mediana é o valor limite de metade dos casos. 
RIBEIRO, L.; MACHADO, I.; SILVA, K. Tempo na ou da justiça criminal brasileira...

Assim, observando a mediana como referente do cálculo do tempo do processo penal, é possível verificar que, no caso de São Paulo, o valor dentro do qual se encaixa metade dos casos analisados é de 726 dias. Já no Rio de Janeiro, esse valor é de 776 dias. Contudo, é importante destacar que esses valores são substancialmente distintos dos médios - coluna (5) - os quais são de 942 e 950, respectivamente. Logo, em cenários como estes, nos quais uma pequena quantidade de casos tem valores muito elevados - coluna (3) - a mediana pode se apresentar como uma medida mais acurada do tempo, já que é menos sujeita a "distorções" dadas por casos excepcionais ${ }^{11}$.

Por outro lado, independente da medida adotada (se média ou mediana), é forçoso notar que o tempo de processamento parece decrescer nos dois casos, de acordo com o ano de distribuição em questão. Seria possível, então, afirmar que, com o passar do tempo, os tribunais tornam-se cada vez mais eficientes no processamento dos delitos que chegam ao seu conhecimento? Para responder a essa questão, os dados da Tabela 4 foram recalculados usando-se como referente o ano da sentença. Os resultados encontram-se sumarizados na Tabela 5.

Tabela 5

Tempo médio de duração de processos de homicídio doloso, segundo ano da sentença. Estados do Rio de Janeiro e de São Paulo - 2000 a 2009

\begin{tabular}{|c|c|c|c|c|c|c|c|}
\hline Ano da sentença & $\begin{array}{l}\mathrm{N} \\
(1) \\
\end{array}$ & $\begin{array}{c}\text { Valor } \\
\text { Mínimo } \\
(2) \\
\end{array}$ & $\begin{array}{c}\text { Valor Máximo } \\
\text { (3) }\end{array}$ & $\begin{array}{c}\text { Mediana } \\
\text { (4) }\end{array}$ & $\begin{array}{l}\text { Média } \\
\text { (5) }\end{array}$ & $\begin{array}{c}\text { Desvio } \\
\text { Padrão } \\
(6) \\
\end{array}$ & $\begin{array}{c}\text { Coeficiente de } \\
\text { variação } \\
\text { (7) }\end{array}$ \\
\hline $\begin{array}{l}\text { São Paulo } \\
2000 \\
2001 \\
2002 \\
2003 \\
2004 \\
2005 \\
2006 \\
2007 \\
2008 \\
2009 \\
\text { Total geral }\end{array}$ & $\begin{array}{c}162 \\
410 \\
743 \\
1342 \\
1903 \\
3455 \\
4315 \\
5261 \\
5130 \\
4785 \\
27569\end{array}$ & $\begin{array}{c}16 \\
17 \\
3 \\
20 \\
3 \\
2 \\
1 \\
2 \\
4 \\
2 \\
1\end{array}$ & $\begin{array}{l}3489 \\
3717 \\
3891 \\
3663 \\
2162 \\
4915 \\
5041 \\
3619 \\
6284 \\
8111 \\
8111\end{array}$ & $\begin{array}{c}317 \\
329 \\
444 \\
552 \\
640 \\
733 \\
854 \\
1015 \\
1119 \\
1263 \\
942\end{array}$ & $\begin{array}{c}151 \\
255 \\
370 \\
464 \\
532 \\
608 \\
678 \\
827 \\
906 \\
1038 \\
726\end{array}$ & $\begin{array}{l}574 \\
388 \\
398 \\
390 \\
432 \\
532 \\
618 \\
744 \\
832 \\
911 \\
754\end{array}$ & $\begin{array}{l}1,81 \\
1,18 \\
0,90 \\
0,71 \\
0,67 \\
0,72 \\
0,72 \\
0,73 \\
0,74 \\
0,72 \\
0,80\end{array}$ \\
\hline $\begin{array}{r}\text { Rio de Janeiro } \\
2000 \\
2001 \\
2002 \\
2003 \\
2004 \\
2005 \\
2006 \\
2007 \\
2008 \\
2009\end{array}$ & $\begin{array}{c}4 \\
55 \\
153 \\
354 \\
400 \\
456 \\
562 \\
514 \\
569 \\
575 \\
3642 \\
\end{array}$ & $\begin{array}{c}58 \\
106 \\
23 \\
2 \\
3 \\
5 \\
1 \\
2 \\
2 \\
2 \\
1 \\
\end{array}$ & $\begin{array}{l}2865 \\
2724 \\
1321 \\
2263 \\
1796 \\
2072 \\
2500 \\
2828 \\
3254 \\
3518 \\
3518 \\
\end{array}$ & $\begin{array}{c}798 \\
447 \\
448 \\
548 \\
682 \\
800 \\
1016 \\
1060 \\
1242 \\
1231 \\
950\end{array}$ & $\begin{array}{c}134 \\
392 \\
448 \\
456 \\
605 \\
742 \\
1016 \\
881 \\
1038 \\
983 \\
776\end{array}$ & $\begin{array}{c}1379 \\
437 \\
273 \\
346 \\
410 \\
506 \\
577 \\
685 \\
830 \\
900 \\
701 \\
\end{array}$ & $\begin{array}{l}1,73 \\
0,98 \\
0,61 \\
0,63 \\
0,60 \\
0,63 \\
0,57 \\
0,65 \\
0,67 \\
0,73 \\
0,74\end{array}$ \\
\hline
\end{tabular}

11 Tal como relatado por Ribeiro (2009), em algumas situações, os tribunais do júri procuram desafogar casos muito antigos, que se encontram parados em sua seção há quase 20 anos e, por isso, muito próximos da prescrição. Assim, se apenas um caso dessa natureza é julgado em um dos anos contemplados na análise, o tempo médio é automaticamente distorcido, posto que esse valor será incrementado em uma quantidade substantiva de tempo em razão de apenas um caso excepcional. Para evitar essas distorções, o mais adequado é utilizar o valor mediano, que não se encontra sujeito a flutuações em razão de casos excepcionais como o descrito. 
Se a média e a mediana geral, dos tempos transcorridos entre a data da distribuição e a data da sentença, em São Paulo e no Rio de Janeiro, não se alteram, como era de se esperar ${ }^{12}$, quando se observa a tendência das médias e medianas anuais é possível perceber que, ano após ano, há um acréscimo no tempo de processamento. Contrastando as Tabelas 4 e 5, pode-se indicar que a tendência de diminuição do tempo de processamento, dada pelo ano da distribuição como referência, inverte-se quando a base da comparação é o ano da sentença; neste caso o tempo aumenta. Este fato pode indicar que, nos dois tribunais, apenas os casos "rápidos" foram distribuídos e encerrados no período coberto pelas bases de dados.

Do ponto de vista metodológico, esses resultados indicam que dependendo do ponto tomado como referente (ano da distribuição ou ano da sentença) e do recorte temporal (número de anos considerado), o tempo do processamento para casos de homicídio doloso pode ser maior ou menor. Logo, a forma de construção da base de dados importa porque ela determina diretamente a quantidade de casos que será levada em consideração e, por conseguinte, os valores da média e da mediana do tempo de processamento.

Para além dessas questões, considerando que tanto a média como a mediana possuem determinados limites enquanto medidas capazes de representar o tempo de processamento, o questionamento que segue é sobre a possibilidade de empregar outras medidas estatísticas para representar o tempo despendido no processo de aplicação da norma abstrata da lei ao fato concreto.

Uma alternativa é a utilização do tempo legal como parâmetro, que permite verificar que proporção de casos é encerrada dentro do prazo previsto pelo CPP. Considerando que o prazo fixado pela nova legislação (após a reforma do CPP de 2008) para o processamento de casos de homicídio doloso é de 270 dias entre a data da distribuição do processo e a data da sentença e que esse prazo não difere muito do vigente antes da reforma, o Gráfico 3 apresenta, para todo o período analisado (2000 a 2009), o percentual de processos concluídos em intervalos sucessivos do prazo legalmente estabelecido para essa fase.

\footnotetext{
12 Já que esses valores são dados pelo total de casos considerados na análise do tempo da fase e, por isso, não estão sujeitos ao número de casos incluídos nos anos de distribuição ou de sentença. Logo, como os casos considerados na Tabela 5 são exatamente os mesmos considerados para a construção da Tabela 4, o valor final não se altera.
}

374 
Gráfico 3

Percentual de casos processados nos intervalos de tempo derivados do prazo legalmente prescrito para duração da fase entre a data da distribuição e a sentença

Estados de São Paulo e Rio de Janeiro (2000 - 2009)

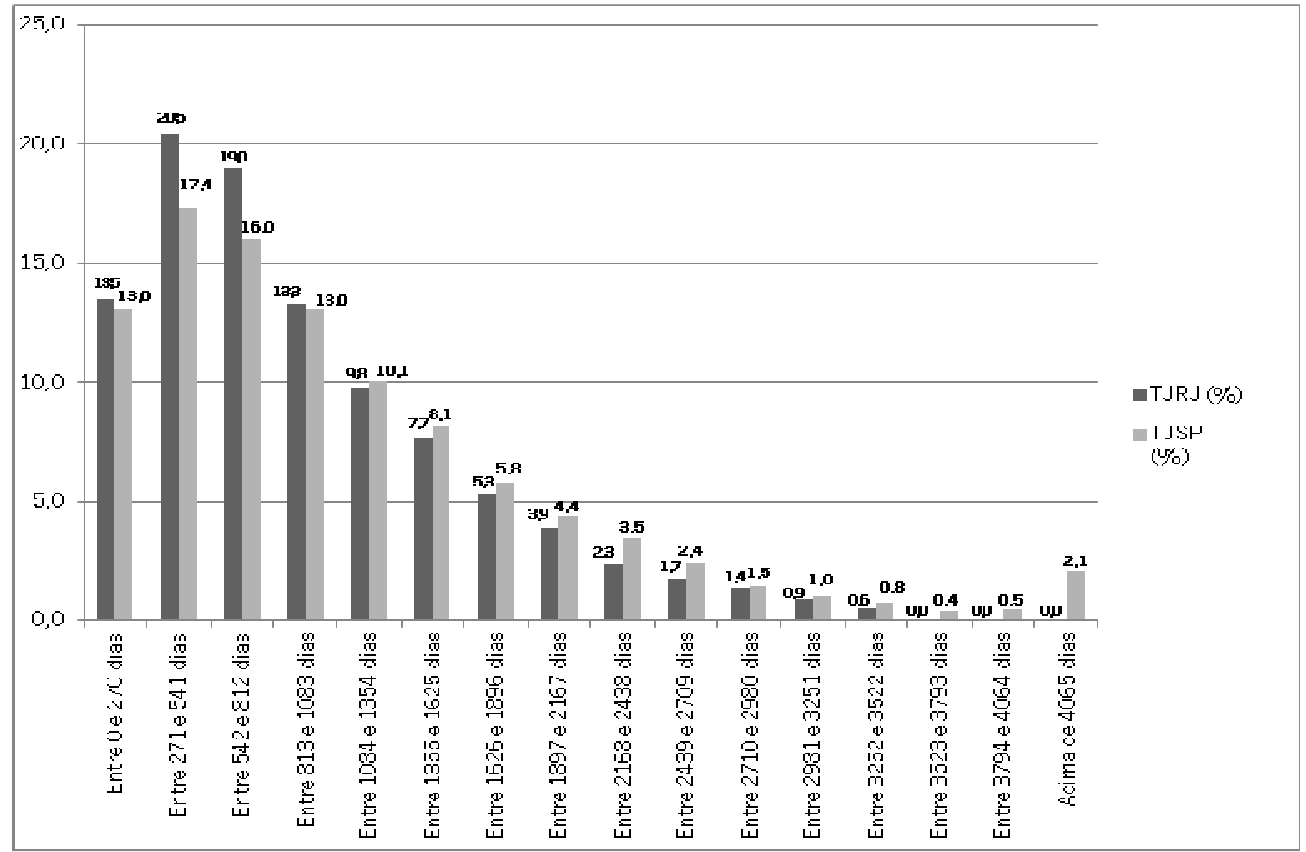

O Gráfico 3 indica que, nos dois tribunais, cerca de $1 / 3$ do total de casos de homicídio doloso processados entre 2000 e 2009, tanto em São Paulo como no Rio de Janeiro, possuem tempos de duração de até 541 dias. Interessante destacar que apenas 13\% dos casos dos dois tribunais respeitam o prazo legalmente previsto de 270 dias como tempo para realização de todos os atos processuais que devem ter lugar entre a distribuição e a sentença. Outro ponto importante a ser realçado é o fato de as faixas com maiores percentuais serem aquelas que representam até quatro vezes o tempo prescrito pelo código para essa fase (ou seja, até 1083 dias). Em boa medida, esses resultados confirmam os anteriores, tal como mostra a Tabela 6: 
OPINIÃO PÚBLICA, Campinas, vol. 18, n², novembro, 2012, p. 355-382

\section{Tabela 6}

\section{Sumário das medidas consideradas para compreensão do tempo entre a data da distribuição e a data da} sentença - Estados de São Paulo e Rio de Janeiro (2000 - 2009)

\begin{tabular}{|l|c|c|l|}
\hline & $\begin{array}{l}\text { Valor Médio } \\
\text { (em dias) }\end{array}$ & $\begin{array}{l}\text { Valor } \\
\text { Mediano } \\
\text { (em dias) }\end{array}$ & $\begin{array}{l}\text { \% de casos que possuem tempo de } \\
\text { processamento de até 1140 dias (4x o } \\
\text { valor do CPP) }\end{array}$ \\
\hline São Paulo & 942 & 726 & 59 \\
Rio de Janeiro & 950 & 771 & 66 \\
\hline
\end{tabular}

Até o momento, foram considerados os casos que possuíam informações completas, ou seja, aqueles que contavam com os campos "data da distribuição" e "data da sentença" devidamente preenchidos. No entanto, de acordo com Vargas (2004), uma técnica que permite que casos com informações incompletas - isto é, com a data da distribuição devidamente preenchida, mas sem a data da sentença (já que essa pode não ter ocorrido) - sejam considerados é a análise de sobrevivência. Esta técnica há muito tempo é utilizada na área de saúde, mas apenas recentemente foi incorporada nos estudos sobre tempo da justiça criminal.

A análise de sobrevivência é técnica particularmente importante para a análise de dados sobre o fluxo de processamento, pois estes apresentam uma configuração de funil com uma grande base, mas um topo bastante estreito, já que no período de um ano vários casos são distribuídos, mas poucos são sentenciados (tal como denotam as primeiras barras do Gráfico 3). Disto resulta um grande número de informações parciais que se perdem - por exemplo, os casos podem possuir informações sobre o tempo despendido até a realização de denúncia e, por isso, em análises tradicionais, não seriam considerados, por não terem ainda alcançado a fase final, de sentença. Com a análise de sobrevivência, estes casos, que também contribuem para que os demais não sejam tão ágeis (por demandarem, por exemplo, a atenção do juiz à sua existência), são considerados no cômputo da mediana final de tempo da fase entre a distribuição do processo e a sentença.

Trata-se, então, de uma técnica importante para estudo do tempo de processamento de um crime por conceder uma medida mais exata do tempo que um tribunal despende na apreciação e julgamento do processo penal, ainda que aquele caso não tenha alcançado o seu desfecho final. Portanto:

“Na análise de sobrevivência a variável dependente é o tempo até a ocorrência do evento. Este tempo é denominado tempo de falha e se refere ao tempo inicial, da escala de medida e da ocorrência do evento de interesse. Os casos que não experimentam o evento são chamados de censura. Mesmo censurados, todos os casos devem ser usados na análise, pois eles fornecem informações sobre o tempo do evento a ser estudado. Ademais, a omissão das censuras no cálculo acarreta vícios nos resultados. Neste sentido, a técnica da análise de sobrevivência se destaca por incorporar à análise a informação contida nos dados censurados" (VARGAS, 2004, p.210). 
RIBEIRO, L.; MACHADO, I.; SILVA, K. Tempo na ou da justiça criminal brasileira...

Para cálculo do tempo mediano entre a data da distribuição e a data da sentença foi utilizado o programa Graphpad Prism, que também é o software usado nas ciências biológicas para a realização da análise de sobrevivência. Nesse programa, são inseridas tão somente duas colunas de informação: na primeira, é computado o tempo entre a data da distribuição e a data da sentença, sendo que para os dados que não experimentaram essa fase, o tempo passa a ser o entre a data da distribuição e a data em que o experimento se encerrou (que, no caso, foi a data de geração do arquivo), já que essa é a última informação possuída sobre o mesmo; na segunda, computa-se 0 (zero) para todos os casos que não alcançaram a fase de sentença e 1 (um) para os casos que seguiram até essa fase. A partir dessas duas colunas, o programa gera uma nova mediana de tempo, que considera tanto os casos que alcançaram a fase de sentença (identificados com 1 na coluna 2), como os que não chegaram até lá (identificados com 0 na coluna 2).

Empregando essa metodologia, é possível verificar que a mediana do tempo de processamento dos casos de homicídio doloso, considerando apenas a fase entre a distribuição e a sentença, é de 3717 dias no TJSP e de 1007 dias no TJRJ (Tabela 7). Esses valores são substantivamente distintos dos 942 dias para o TJSP e 950 para o TJRJ, resultantes do emprego da metodologia tradicional, que considera apenas os casos com informações completas.

\section{Tabela 7}

Mediana do tempo entre a data da distribuição e a data da sentença, calculada pela técnica de análise de sobrevivência - apenas casos de homicídio doloso Estados de São Paulo e Rio de Janeiro (2000 a 2009)

\begin{tabular}{|l|l|l|}
\hline Indicadores & SP & RJ \\
\hline Total de casos & 124835 & 5671 \\
\# células sem informação & 0 & 0 \\
\# casos sem sentença & 97266 & 2029 \\
\# casos com sentença & 27569 & 3642 \\
\hline Mediana de tempo (sobrevivência) & 3717 & 1007 \\
\hline
\end{tabular}

Logo, utilizando a técnica de análise de sobrevivência para cálculo da mediana do tempo entre a data da distribuição e a data da sentença, os cenários apresentados são totalmente distintos dos analisados anteriormente. Agora, a mediana de tempo de São Paulo é quase três vezes a mediana de tempo do Rio de Janeiro. Além disso, as duas são bem superiores ao cálculo tradicional, quando são considerados apenas os casos que percorreram todas as fases. Para o TJSP, a medida apresentada pela análise de sobrevivência é 5,1 mais ampla que a anteriormente apresentada; já para o TJRJ, essa medida é apenas 1,3 vezes maior (voltar às Tabelas 4 e 5).

Mas, o que explica tamanha diferença entre as medianas dos dois casos? O fato de que, no Rio de Janeiro, o número percentual de casos sem sentença, ou seja, a ser acrescido pela análise de sobrevivência é muito menor do que em São Paulo (no TJRJ são 35\% dos casos sem sentença, enquanto 
OPINIÃO PÚBLICA, Campinas, vol. 18, n², novembro, 2012, p. 355-382

em São Paulo são $78 \%$ sem sentença). E, caso a hipótese anteriormente apresentada esteja correta ${ }^{13}$, especialmente para o caso do Rio de Janeiro, a estimativa alcançada com o emprego da técnica de análise de sobrevivência também está equivocada, já que não contempla todos os casos que demandavam atenção dos juízes e serventuários, impedindo que esses dedicassem o seu tempo apenas aos casos que alcançaram a fase final.

Diante desses resultados, é possível afirmar que as estratégias de análise devem ser diferenciadas dependendo da natureza dos casos inseridos em cada base de dados.

(1) Para bases de dados que possuem apenas casos com informações completas, as medidas a serem utilizadas devem ser as de tendência central, quais sejam: a média e a mediana. Contudo, para verificar se, de fato, a média é capaz de sumarizar o tempo de processamento de um dado tribunal, é indispensável o cálculo do coeficiente de variação, dado pela razão entre o desvio padrão e a própria média. Caso o valor do coeficiente de variação seja maior do que zero, uma alternativa é utilizar o valor mediano, que é aquele que divide todos os casos em duas séries de igual tamanho.

(2) Para bases de dados que possuem tanto casos com informações completas como ainda casos com informações censuradas (isto é, que foram iniciados, mas que não foram encerrados), a melhor estratégia para a mensuração do tempo despendido pelos tribunais é a partir do emprego da análise de sobrevivência e, assim, o programa Graphpad Prism apresenta-se como uma boa alternativa, dado que a sua simplicidade garante que a análise dos casos ocorra sem maiores percalços ou riscos de estimativas enviesadas.

\section{Comentários Finais}

Não obstante o teor quantitativo do artigo, os comentários finais são de ordem mais filosófica, em virtude das reflexões produzidas após o exercício empreendido e os resultados encontrados. 0 ponto enfatizado converge para a urgência em encontrar uma medida mais adequada aos estudos sociológicos que visam compreender o funcionamento do sistema de justiça criminal no Brasil, principalmente para a questão do tempo processual penal. Para tanto, optou-se por mencionar os principais estudos sobre este tema desenvolvidos no Brasil nos últimos 10 anos, apontando as fontes de dados utilizadas, os métodos de análise escolhidos pelos pesquisadores, as medidas adotadas e os principais resultados.

Além disso, para uma reflexão eminentemente metodológica, foram utilizadas as bases de dados fornecidas pelos Tribunais de Justiça dos Estados de São Paulo e Rio de Janeiro, obtidas mediante solicitação formal quando da pesquisa "Pensando o Direito", visando abarcar todos os processos de homicídios iniciados entre 2000 e 2009. Análises quantitativas foram empreendidas de modo a observar prioritariamente o tempo despendido em ambos os tribunais. Foram comparados os valores encontrados para a média e a mediana, medidas de tendência central. Além disso, foram observados os valores do coeficiente de variação e, diante disso, foi possível considerar que a média não

\footnotetext{
${ }^{13}$ A hipótese era de que esse banco de dados não seria capaz de refletir a realidade do Rio de Janeiro porque não incluía todos os casos que se encontravam tramitando no TJRJ, mas, majoritariamente, os iniciados e encerrados entre os anos de 2000 e 2009.
} 
RIBEIRO, L.; MACHADO, I.; SILVA, K. Tempo na ou da justiça criminal brasileira...

se mostra como a melhor medida quando busca-se mensurar o tempo da justiça criminal no Brasil, principalmente quando se trata de bancos de dados com informações incompletas. Neste sentido, os valores obtidos através do cálculo da mediana mostraram-se mais razoáveis. Ainda pouco satisfeitos com tais análises, optamos por calcular a mediana através do método de análise de sobrevivência, escolha que se mostrou pertinente e mais esclarecedora considerando a natureza dos dados analisados, sobretudo quando de bases de dados com informações incompletas

Mas... "como medir o tempo do direito?". A pergunta que abre este artigo pode ser representativa de duas problemáticas distintas abordadas ao longo do texto. Primeiramente, pode exprimir a perplexidade diante de problemas fáticos na coleta de dados a respeito do fluxo de tempo nos processos judiciais brasileiros. Conforme visto, essas informações empíricas são de difícil coleta pelos pesquisadores tanto por inexistência ou baixa qualidade dos dados, quanto por negativa de acesso a eles; ou por falta de integração entre as diversas instâncias nas quais eles são produzidos (o que faz com que cada organização tenha um banco de dados que não se comunica com os demais). Diante desse quadro, sem dúvida, cabe perguntar: como medir o tempo do direito se os elementos que tornariam essa mensuração possível mostram-se inacessíveis por uma série de razões?

Mas a interrogação que iniciou este artigo pode também referir-se a outra questão, de dimensão mais teórica. Trata-se da dificuldade das medidas utilizadas para contabilizar efetivamente o tempo do direito e os tipos de interpretação possíveis que tais medidas podem ter. Nesse sentido, a pergunta ganharia outros contornos e complementos. Sendo assim, como medir o tempo do Direito? Tomando como ponto de referência a data da distribuição ou a data da sentença? A média dos tempos ou a mediana? Que outros tipos de análise estatística poderiam contribuir para esse estudo? Quais dimensões do processo cada uma dessas medidas expressa de melhor forma?

Esses dois ângulos através dos quais a pergunta "como medir o tempo do direito?" pode ser encarada demandam soluções distintas, mesmo que, em alguma medida complementares. À perplexidade dos pesquisadores perante as dificuldades fáticas em lidar com a coleta de dados sobre o fluxo de tempo da justiça brasileira deve ser dada uma resposta de ação política. Os sistemas de informação da polícia e dos tribunais precisam ser aprimorados, unificados e tornados mais acessíveis, fornecendo informações de qualidade aos interessados em examinar o tema, inclusive por uma questão democrática. Afinal, deve-se lembrar que o sistema de justiça presta um serviço público e precisa poder ser acompanhado pelo público e não pode atuar sob uma lógica de segredo.

Já à questão mais abstrata de como medir objetivamente um transcurso de tempo que pode ter apreensões subjetivas tão distintas, como um processo criminal, a resposta a ser dada é menos uma fórmula pronta do que um convite ao diálogo capaz de gerar respostas múltiplas, dependentes das filiações intelectuais dos debatedores. Um diálogo preferencialmente multidisciplinar, que congregue contribuições sociológicas, estatísticas, filosóficas, jurídicas, econômicas, etc. Afinal, mais do que questões meramente metodológicas, essa investigação envolve aspectos teóricos incidentes sobre o que é exatamente o tempo do direito. Por exemplo, o tempo do direito é o tempo sequencial irreversível e de medida cumulativa - do grego chronos - ou o tempo da oportunidade, do momento correto, de duração transcendente - do grego kairós? Ou alguma mistura dos dois? 
OPINIÃO PÚBLICA, Campinas, vol. 18, n², novembro, 2012, p. 355-382

Mesmo exigindo soluções distintas, as duas frentes de análise da questão apelam a soluções complementares. Por um lado, os tipos de dados relevantes, cuja produção pelo sistema de justiça brasileiro deve ser exigida, dependem das possíveis respostas teóricas ao que é importante na mensuração do tempo do direito. Por outro lado, o debate teórico e metodológico sobre como o tempo do direito pode e deve ser medido é enriquecido por dados empíricos, capazes de mostrar como se manifestam faticamente as diversas dimensões da passagem do tempo no direito.

Apesar de divergências a respeito de qual das duas facetas do tempo deve prevalecer na análise do tempo do direito, é difícil negar que o sistema de justiça está envolvido com as dimensões tanto da eficiência, quanto da correção e que busca equilibrar-se entre as duas, isto é, de alguma maneira, equilibrar-se entre "chronos" e "kairós". É inegável que a palavra de autoridade de um julgamento jurídico busca se inscrever num tempo transcendente, possivelmente contrapondo-se ao imediatismo de uma temporalidade cronológica. Por exemplo, mesmo que o interesse de curto prazo da mídia, focado no retorno de público dado pela manchete, condene determinada pessoa, o sistema de justiça pode absolvê-la, já que ele não está preocupado apenas com a passagem unilateral do tempo, mas em reafirmar compromissos de justiça do passado em expectativas para o futuro. Nesse sentido, a busca pela correção coloca o sistema de justiça em relação direta com Kairós, não apenas a palavra grega para o tempo da oportunidade, mas também a entidade divina capaz de se contrapor ao tirânico deus Chronos, impiedoso na caçada e destruição de suas criações, tão bem retratado no assustador quadro de Goya que representa Saturno - nome romano para Chronos - devorando um de seus filhos.

Mas também é inegável que o tempo do direito insere-se numa cronologia irreversível e precisa atender a critérios de eficiência, possuindo assim também a sua dimensão de chronos. Por exemplo, um longo percurso de tempo certamente serviria melhor à apreciação de um delito nas diversas instâncias policiais e judiciárias e mesmo uma maior quantidade de instâncias para a avaliação desse delito serviria a um julgamento mais preciso e confiável para a formulação de juízos de culpabilidade ou inocência. Mas a eficiência exige respostas ágeis do sistema de justiça e, além disso, novos casos chegam para serem processados e casos antigos não podem emperrar seu andamento, o que exige limites na distensão temporal do processo. Sendo assim, quais medidas são razoáveis para se buscar a correção sem sacrificar a eficiência e vice-versa?

Esse é um debate que ainda precisa ser feito e que, no caso brasileiro, carece de informações empíricas capazes de sustentá-lo. Sem acesso a esses dados, torna-se difícil avaliar em que medida os chronos e kairós efetivam-se e contrapõem-se nos processos judiciais. Tendo isso em vista, este artigo apresenta-se muito mais como um ponto de partida, oferecendo perguntas a esse debate, do que como um ponto de chegada, capaz de oferecer respostas mais substantivas. O que fica como resposta substantiva é a necessidade urgente de tornar mais acessíveis os dados do sistema de justiça para que o próprio debate possa ser feito. Se Chronos e Kairós enfrentam-se no sistema de justiça, nós precisamos ter acesso a esse embate. 


\section{Referências Bibliográficas}

Batitucci, E. et al. Fluxo do Crime de Homicídio no Sistema de Justiça Criminal de Minas Gerais. $30^{\circ}$ Encontro da Associação Nacional de Pós Graduação e Pesquisa em Ciências Sociais, Caxambu, Anais... ANPOCS, 2006.

BECKER, H. S. Segredos e truques da pesquisa social. Rio de Janeiro: Zahar, 2007.

CANo, I.; DuARTE, T. "Mensurando a impunidade no sistema de justiça criminal do Rio de Janeiro". In: Segurança, Justiça e Cidadania, vol. 4, p. 10.43, 2010.

FARIA, J. E. "O sistema brasileiro de Justiça: experiência recente e futuros desafios". Estudos Avançados, São Paulo, vol.18, n’51, ago. 2004.

Ferreira, A. C. e Pedroso, J. P. "Os tempos da justiça: ensaio sobre a duração e morosidade processual". Oficina do CES, vol.99. 1997.

KANT DE LIMA, R. "Cultura jurídica e práticas policiais: a tradição inquisitorial”, Revista Brasileira de Ciências Sociais, São Paulo, ANPOCS, 4 (10), p. 65.84, 1989.

. Ensaios de Antropologia e de Direito: acesso à justiça e processos institucionais de administração de conflitos e produção da verdade jurídica em uma perspectiva comparada. Rio de Janeiro: Editora Lúmen Júris, 2008 , $289 p$.

LIMA, R.; SINHORETTO, J. Os estudos de fluxo do sistema de justiça criminal e o tratamento integrado de informações. In: LIMA, R. (org.). Entre Palavras e Números: violência, democracia e segurança pública no Brasil. São Paulo: Alameda Casa Editorial, 2010.

Ost, F. O tempo do direito. Bauru: Edusc, 2005.

PINHEIRO, P. S. et al. Continuidade autoritária e construção da democracia. São Paulo: NEV/USP, 1999.

RELATÓRIO ICJ, BRASIL. Índice de Confiança na Justiça. Resultados da mensuração realizada no terceiro trimestre de 2011. São Paulo: Fundação Getúlio Vargas, 2011.

Ribeiro, L. Administração da Justiça Criminal na cidade do Rio de Janeiro: uma análise dos casos de homicídio. Rio de Janeiro: IUPERJ (tese de doutorado). 2009.

"A Produção Decisória do Sistema de Justiça Criminal para o Crime de Homicídio: Análise dos Dados do Estado de São Paulo entre 1991 e 1998". Dados - Revista de Ciências Sociais, Rio de Janeiro, vol. 53, n 1, p. 159.193, 2010 .

RiBeIRO, L.; CRUZ, M.; BatitucCI, E. Morosidade necessária ou impunidade? O tempo dos Tribunais do Júri em Minas Gerais. XIV . Congresso da Sociedade Brasileira de Sociologia. Rio de Janeiro, Anais... SBS, 2009.

RIBEIRO, L.; DUARTE, T. Padrões de seleção no processamento dos homicídios dolosos: o tempo dos casos julgados pelo Tribunal de Justiça do Rio de Janeiro entre os anos 2000 e 2007. $32^{\circ}$ Encontro da Associação Nacional de Pós Graduação e Pesquisa em Ciências Sociais, Caxambu, Anais... ANPOCS, 2008.

Ruschel, A. Análise do tempo dos Processos Penais de homicídio no Fórum de Justiça de Florianópolis julgados em 2004. Tese de Doutorado. Universidade Federal de Santa Catarina, 2006.

SILVA, K. A. "O papel dos tipos de homicídios dolosos na construção social da incriminação dos sujeitos pelos promotores de justiça: Belo Horizonte, processos em andamento entre 2007 e 2009". Dilemas: Revista de Estudos de Conflito e Controle Social, vol. 8, p. 101-123, 2010.

VARGAS, J. D. Estupro: que justiça? Rio de Janeiro: IUPERJ (Tese de doutorado), 2004.

Vargas, J.; BLAVAStKy, I. e Ribeiro, L. Metodologia de tratamento do tempo e da Morosidade processual na Justiça Criminal. Brasília: Ministério da Justiça, 2005. 
"Tempo da Justiça Criminal: metodologia de tratamento do tempo e da morosidade processual na justiça criminal. Segurança, Justiça e Cidadania, vol. 4, p. 45.72, 2010.

Ludmila Ribeiro·ludmila.ribeiro@gmail.com

Igor Machado · igorsuzano@gmail.com

Klarissa Silva·silva.klarissa@gmail.com

Submetido à publicação em agosto de 2011. Versão final aprovada em dezembro de 2011. 